\title{
The SAL-PAP Chloroplast Retrograde Pathway Contributes to Plant Immunity by Regulating Glucosinolate Pathway and Phytohormone Signaling
}

\author{
Yasuhiro Ishiga, ${ }^{1,2,+}$ Mutsumi Watanabe, ${ }^{3}$ Takako Ishiga, ${ }^{1,2}$ Takayuki Tohge, ${ }^{3}$ Takakazu Matsuura, ${ }^{4}$ \\ Yoko Ikeda, ${ }^{4}$ Rainer Hoefgen, ${ }^{3}$ Alisdair R. Fernie, ${ }^{3}$ and Kirankumar S. Mysore ${ }^{1, \dagger}$ \\ ${ }^{1}$ Noble Research Institute, LLC, Ardmore, OK 73401, U.S.A.; ${ }^{2}$ Faculty of Life and Environmental Sciences, University of \\ Tsukuba, 1-1-1 Tennodai, Tsukuba, Ibaraki 305-8572, Japan; ${ }^{3}$ Max Planck Institute of Molecular Plant Physiology, Potsdam- \\ Golm, Germany; and ${ }^{4}$ Institute of Plant Science and Resources, Okayama University, Kurashiki, Okayama, 710-0046, Japan
}

Accepted 11 July 2017.

\begin{abstract}
Chloroplasts have a crucial role in plant immunity against pathogens. Increasing evidence suggests that phytopathogens target chloroplast homeostasis as a pathogenicity mechanism. In order to regulate the performance of chloroplasts under stress conditions, chloroplasts produce retrograde signals to alter nuclear gene expression. Many signals for the chloroplast retrograde pathway have been identified, including chlorophyll intermediates, reactive oxygen species, and metabolic retrograde signals. Although there is a reasonably good understanding of chloroplast retrograde signaling in plant immunity, some signals are not wellunderstood. In order to understand the role of chloroplast retrograde signaling in plant immunity, we investigated Arabidopsis chloroplast retrograde signaling mutants in response to pathogen inoculation. sal1 mutants (fry 1-2 and $a l x 8$ ) responsible for the SAL1-PAP retrograde signaling pathway showed enhanced disease symptoms not only to the hemibiotrophic pathogen Pseudomonas syringae pv. tomato DC3000 but, also, to the necrotrophic pathogen Pectobacterium carotovorum subsp. carotovorum EC1. Glucosinolate profiles demonstrated the reduced accumulation of aliphatic glucosinolates in the fry 1-2 and $a l x 8$ mutants compared with the wild-type Col-0 in response to DC3000 infection. In addition, quantification of multiple phytohormones and analyses of their gene expression profiles revealed that both the salicylic acid (SA)- and jasmonic acid (JA)-mediated signaling pathways were down-regulated in the fry $1-2$ and $a l x 8$ mutants. These results suggest that the SAL1-PAP chloroplast retrograde pathway is involved in plant immunity by regulating the SA- and JA-mediated signaling pathways.
\end{abstract}

Plants are surrounded by an enormous number of microorganisms, including potential pathogens. They have, therefore, developed defense systems that efficiently detect invading pathogens and induce an array of defense responses. The first layer of this defense system is based on the detection of pathogen- or microbe-associated molecular patterns (PAMPs or MAMPs), including the flagella protein (flagellin), lipopolysaccharide, and elongation factor $\mathrm{Tu}$, through plant pattern-recognition receptors

${ }^{\dagger}$ Corresponding authors: K. S. Mysore; E-mail: ksmysore@noble.org and Y. Ishiga; E-mail: ishiga.yasuhiro.km@u.tsukuba.ac.jp

*The $\boldsymbol{e}$-Xtra logo stands for "electronic extra" and indicates that four supplementary figures and one supplementary table are published online.

() 2017 The American Phytopathological Society present at the plant cell surface, resulting in PAMP-triggered immunity (PTI) (Zipfel 2008). Moreover, recognition of avirulent effectors from pathogens by plant resistance $(\mathrm{R})$ proteins trigger a second line of defense, resulting in effector-triggered immunity (ETI) (Cui et al. 2015). It is known that PTI and ETI activate similar sets of plant defense responses, including the oxidative burst, callose ( $\beta$-1,3-glucan) deposition in the cell wall, and the induction of defense gene expression. However, ETI is more prolonged and robust than PTI (Tsuda and Katagiri 2010; Zhang and Zhou 2010; Zipfel 2008).

Phytohormones play an important role in many aspects of plant development and responses to biotic and abiotic stresses. The major phytohormones responsible for mediating defense responses to pathogens are salicylic acid (SA) and jasmonic acid (JA) (Pieterse et al. 2012; Robert-Seilaniantz et al. 2011). To date, numerous studies have demonstrated the role of these phytohormones in plant defense for a multitude of plant species (Pieterse et al. 2012; Robert-Seilaniantz et al. 2011). SA is the most prevalent defense phytohormone produced in plants after exposure to biotrophic and hemibiotrophic pathogens. SA is also considered as a major signal for ETI and systemic acquired resistance ( $\mathrm{Fu}$ and Dong 2013). On the other hand, JA is the most prevalent defense phytohormone produced in response to necrotrophic pathogens (Pieterse et al. 2012; Robert-Seilaniantz et al. 2011). Often, interactions between SA and JA signaling pathway happen during plant immune responses. It is well-known that SA and JA, most of the time, act antagonistically (Pieterse et al. 2012; Robert-Seilaniantz et al. 2011). Chloroplasts are involved in the biosynthesis of phytohormones such as SA and JA (Boatwright and Pajerowska-Mukhtar 2013; Kombrink 2012). Therefore, chloroplasts have a crucial role in plant immunity against pathogens (Nomura et al. 2012). Increasing evidence suggests that phytopathogens target chloroplast homeostasis as a pathogenicity mechanism (Ciuffetti et al. 2010; Ishiga et al. 2009, 2012). For example, the phytotoxin coronatine (COR) produced from Pseudomonas syringae pv. tomato DC3000 was reported to target chloroplast reactive oxygen species (ROS) homeostasis in modulating disease development (Ishiga et al. 2009, 2012).

The chloroplasts of higher plants take part not only in the process of photosynthesis but, also, in the synthesis of numerous compounds, including secondary metabolites, fatty acids, and amino acids (Poonam et al. 2015; Sun and Zerges 2015). The chloroplast produces retrograde signals to change the nuclear gene expression in order to regulate chloroplast biogenesis, maintain homeostasis, or optimize chloroplast performance under stress conditions including pathogen attack (Chi et al. 2013, 
2015). Many signals for the chloroplast retrograde pathway have been identified, including chlorophyll intermediates, ROS, and metabolic retrograde signals (Chi et al. 2013, 2015). A recent study demonstrated that an isoprenoid precursor, methylerythritol cyclodiphosphate, derived from the methylerythritol phosphate pathway, functions in retrograde biotic stress signaling by regulating SA accumulation (Xiao et al. 2012). In addition, SAL1PAP retrograde signaling has been shown to have a crucial role in drought and high light stresses (Estavillo et al. 2011; Wilson et al. 2009). Estavillo et al. (2011) demonstrated that $3^{\prime}$-phosphoadenosine 5 '-phosphate (PAP) functions as a retrograde signaling molecule and PAP levels were degraded by phosphatase SAL1 (also called FRY1) during stress (Estavillo et al. 2011).

SAL1 encodes a bifunctional enzyme modulating 3' (2'),5'bisphosphate nucleotidase and inositol polyphosphate 1-phosphatase activities (Quintero et al. 1996). Several mutants with mutation in the $S A L 1$ gene have been identified by genetic screens and have been characterized. The first mutant (ethylmethane sulphonate [EMS]) identified in this gene was called fieryl (fryl), which had more abscisic acid (ABA) induction (Xiong et al. 2001). Since then, several T-DNA insertion (fryl-3 and fry 1-5) and EMS mutant alleles have been identified (Hirsch et al. 2011). Another EMS mutant allele, alx8 (altered expression of apx2 8) was identified in a screen for elevated expression of ascorbate peroxidase 2 under high and low light conditions (Wilson et al. 2009). It has been shown that mutation of the $S A L 1$ gene affects a wide range of cellular processes, because several important cellular metabolites, including inositol 1,4,5-triphosphate (IP3), 3'-phosphoadenosine 5'-phosphosulfate (PAPS), and PAP are substrates for SAL1 (Chen and Xiong 2010; Kim and von Arnim 2009; Lee et al. 2012; Robles et al. 2010; Rodríguez et al. 2010; Wilson et al. 2009; Xiong et al. 2001). Therefore, almost all the different phenotypes of Arabidopsis sall mutants have been attributed to inhibition of IP3 signaling (Wilson et al. 2009; Xiong et al. 2001) and dysfunction of exoribonucleases of the $5^{\prime}-3^{\prime}$ exoribonuclease (XRN) family by the accumulation of PAP (Chen and Xiong 2010; Estavillo et al. 2011; Kim and von Arnim 2009). Several recent reports revealed that Arabidopsis sall mutants, including fry 1-4, fry 1-5, and fry 1-6, have severe developmental defects such as reduced growth, late flowering, and root development because of dysfunction of XRN family proteins by PAP accumulation (Chen and Xiong 2010; Gy et al. 2007; Kim and von Arnim 2009). In addition, sall mutants are known to exhibit a drought-tolerance phenotype (Estavillo et al. 2011; Wilson et al. 2009). Interestingly, the use of tilling array and RNA-seq revealed the accumulation of noncoding RNAs, including micro-RNAs in the fry 1-6 mutant (Kurihara et al. 2012). Further, the alx 8 mutant allele has been shown to be drought tolerant (Rossel et al. 2006). A recent study also demonstrated that the PAP signal from chloroplast regulates programmed cell death in Arabidopsis (Bruggeman et al. 2016). Although there is a good understanding of chloroplast retrograde signaling in biotic and abiotic stresses (Chan et al. 2016a; Lemos et al. 2016; Xiao et al. 2012), the role of SAL1-PAP-mediated retrograde signaling in conferring plant immunity against pathogens is not understood.

Glucosinolates are sulfur- and nitrogen-containing plant metabolites and are known to be classified into three categories based on the chemical structure of their amino acid precursors, i.e., aliphatic glucosinolates, indole glucosinolates, and aromatic glucosinolates (Ishida et al. 2014). Around 130 glucosinolates have been reported from plants of the order Brassicales (Agerbirk and Olsen 2012). Glucosinolates have been shown to play a critical role in the plant immune system, indole glucosinolates derived from tryptophan have, especially, been reported to play an important role in the nonhost resistance of Arabidopsis against fungal pathogens (Bednarek et al. 2009; Clay et al. 2009; Hiruma et al. 2013; Stotz et al. 2011). In addition to indole glucosinolates, aliphatic glucosinolates are also known to have a function in nonhost resistance of Arabidopsis against nonhost bacterial pathogens, such as $P$. syringae pv. tomato T1, $P$. syringae pv. tabaci, and $P$. syringae pv. glycinea (Andersson et al. 2015; Fan et al. 2011).

In this study, we demonstrated that the sall mutants showed enhanced susceptibility not only to the hemibiotrophic pathogen $P$. syringae pv. tomato DC3000 but, also, to a necrotrophic pathogen, Pectobacterium carotovorum subsp. carotovorum EC1. Metabolome analyses identified a correlation between aliphatic glucosinolates production and plant defense responses against DC3000. Furthermore, we demonstrated that an Arabidopsis sal1 mutant is compromised in SA- and JA-mediated signaling pathways. Our results suggest a role for the SAL1PAP chloroplast retrograde pathway in plant immunity.

\section{RESULTS}

The retrograde signaling mutant fry 1-2 showed enhanced disease symptoms against $P$. syringae pv. tomato $\mathrm{DC} 3000$.

In order to understand the role of chloroplast retrograde signaling in plant immunity, we investigated Arabidopsis chloroplast retrograde signaling mutants involved in the SAL1-PAP signaling pathway (fry 1-2) (Lee et al. 2012), the redox signaling pathway (stn7 [state transition-deficient mutant 7]) (Tikkanen et al. 2012), and the singlet oxygen signaling pathway (exl [executerl] and ex2) (Lee et al. 2007) in response to pathogens. Two-week-old Arabidopsis plants, including wild type (Col-0), fry 1-2, stn7, ex1, and ex2 mutants grown on Murashige and Skoog (MS) agar were flood-inoculated with DC3000 and were monitored for disease progression. The wild-type Col-0 plants showed typical disease symptoms, consisting of chlorosis with water-soaked lesions in response to DC3000 (Fig. 1A). The $\sin 7$, ex1, and ex2 mutants showed disease symptoms similar to Col-0 plants (Fig. 1A). However, the fry 1-2 mutant plants showed severe chlorosis and necrotic cell death that was significantly more than shown by the Col-0 plants (Fig. 1A). To determine whether the severe disease symptoms in the fry $1-2$ mutant plants are due to more bacterial growth, the bacterial population was evaluated at 1,2 , and 4 days postinoculation (dpi). Interestingly, no significant differences were observed in the populations of DC3000 in the fryl-2, stn7, exl, and ex2 mutants compared with wildtype Col-0 plants (Fig. 1B). These results suggest that the FRYImediated SAL1-PAP chloroplast retrograde signaling pathway plays a role in disease symptom development.

To further investigate the role of the SAL1-PAP chloroplast retrograde signaling pathway in plant immunity, we next generated Arabidopsis lines overexpressing SAL1 (Supplementary Fig. S1) and inoculated them with DC3000. In addition to fry 1-2, we also investigated another fry 1 mutant allele, alx 8 . Both fry 1-2 and al 88 mutants were slightly dwarf and had rounded leaf margins. SAL1-overexpression plants were not significantly different from the wild-type Col-0 with respect to disease symptom development and bacterial populations, whereas the fry $1-2$ and al $x 8$ plants showed severe chlorosis and necrotic cell death in response to DC3000 infection when compared with the wild-type Col-0 plants (Figs. 2A and B). In addition, consistent with enhanced chlorosis, a lower level of chlorophyll accumulation was observed in the fry $1-2$ and al $x 8$ mutant plants inoculated with DC3000 compared with Col-0 and SAL1overexpression plants (Fig. 2C).

\section{SAL1-PAP chloroplast retrograde signaling mutants are compromised in ETI.}

To determine if SAL1-PAP chloroplast retrograde signaling plays a role in plant immunity, especially ETI, fryl-2, and al 88 mutants and the SAL1-overexpression plants were flood-inoculated 
with DC3000 carrying either AvrRpt2 or AvrRpm1. Wild-type (Col-0) and the sall mutants have $R$ genes, RPS2 and RPM1, that can recognize AvrRpt2 and AvrRpm1, respectively. As expected, no visible disease symptoms were observed in the Col-0 plants due to gene-for-gene resistance (ETI) (Fig. 3A). SAL1-overexpression plants also did not show any difference in disease symptoms (Fig. 3A). Interestingly, some leaves of fryl-2 and alx 8 mutants showed symptoms of chlorosis in response to avirulent DC3000 carrying either AvrRpt2 or AvrRpml (Fig. 3A). To determine whether the enhanced chlorosis symptoms in the fry $1-2$ and alx 8 mutant plants was due to increased bacterial populations, the bacterial titer was measured, at $3 \mathrm{dpi}$, in plants inoculated with DC3000 carrying either AvrRpt 2 or AvrRpm1. Consistent with the enhanced disease symptoms, increased bacterial populations were observed in the fry 1-2 and al $x 8$ mutant plants in comparison with the Col-0 and SAL1-overexpressing plants (Fig. 3B). These results demonstrate a role for SAL1-PAP chloroplast retrograde signaling in promoting plant immunity, especially ETI.

SAL1-PAP chloroplast retrograde signaling mutants show enhanced susceptibility to necrotrophic pathogens.

To further investigate the role for SAL1-PAP chloroplast retrograde signaling in plant immunity, we challenged the necrotrophic bacterial pathogen Pectobacterium carotovorum subsp. carotovorum EC1 to the wild-type Col-0, the fryl-2 and alx 8 mutant plants, and SAL1-overexpression plants. EC1 is well-known as a soft-rot pathogen causing serious damage to a wide variety of crop species (Mansfield et al. 2012). EC1 is also known to cause soft rot on Arabidopsis (Higashi et al. 2008). As shown in Figure 4A, the fry $1-2$ and al $x 8$ mutant plants clearly showed enhanced susceptibility to EC1 when compared with the wild-type Col-0 and $S A L 1$-overexpression plants (Fig. 4A). To quantify the susceptibility of the Arabidopsis plants to EC1, we categorized disease symptoms on three different levels by their severity, according to a previous study (Higashi et al. 2008). The Col-0 and SAL1-overexpression plants showed severe disease symptoms (level 2) in approximately $10 \%$ of the inoculated regions at $24 \mathrm{~h}$ after inoculation and approximately $30 \%$ at $48 \mathrm{~h}$ after inoculation. However, the fryl-2 and alx 8 mutants developed severe disease symptoms (level 2) in 45 to $55 \%$ of the inoculated regions at $24 \mathrm{~h}$ after inoculation and 85 to $90 \%$ at $48 \mathrm{~h}$ after inoculation. These results suggest a role for SAL1PAP chloroplast retrograde signaling in promoting plant immunity against necrotrophic pathogens.

Glucosinolate profiles reveal the reduced accumulation of aliphatic glucosinolates in the SAL1-PAP chloroplast retrograde signaling mutants.

It has been demonstrated that the loss-of-function alleles of $S A L 1$ result in numerous phenotypes because its substrates include several important cellular metabolites, such as IP3, PAPS, and PAP (Chen and Xiong 2010; Kim and von Arnim 2009; Robles et al. 2010; Rodríguez et al. 2010; Xiong et al. 2001). A recent study demonstrated that the fryl mutant exhibited a sulfur metabolic phenotype (Lee et al. 2012). Therefore, we investigated
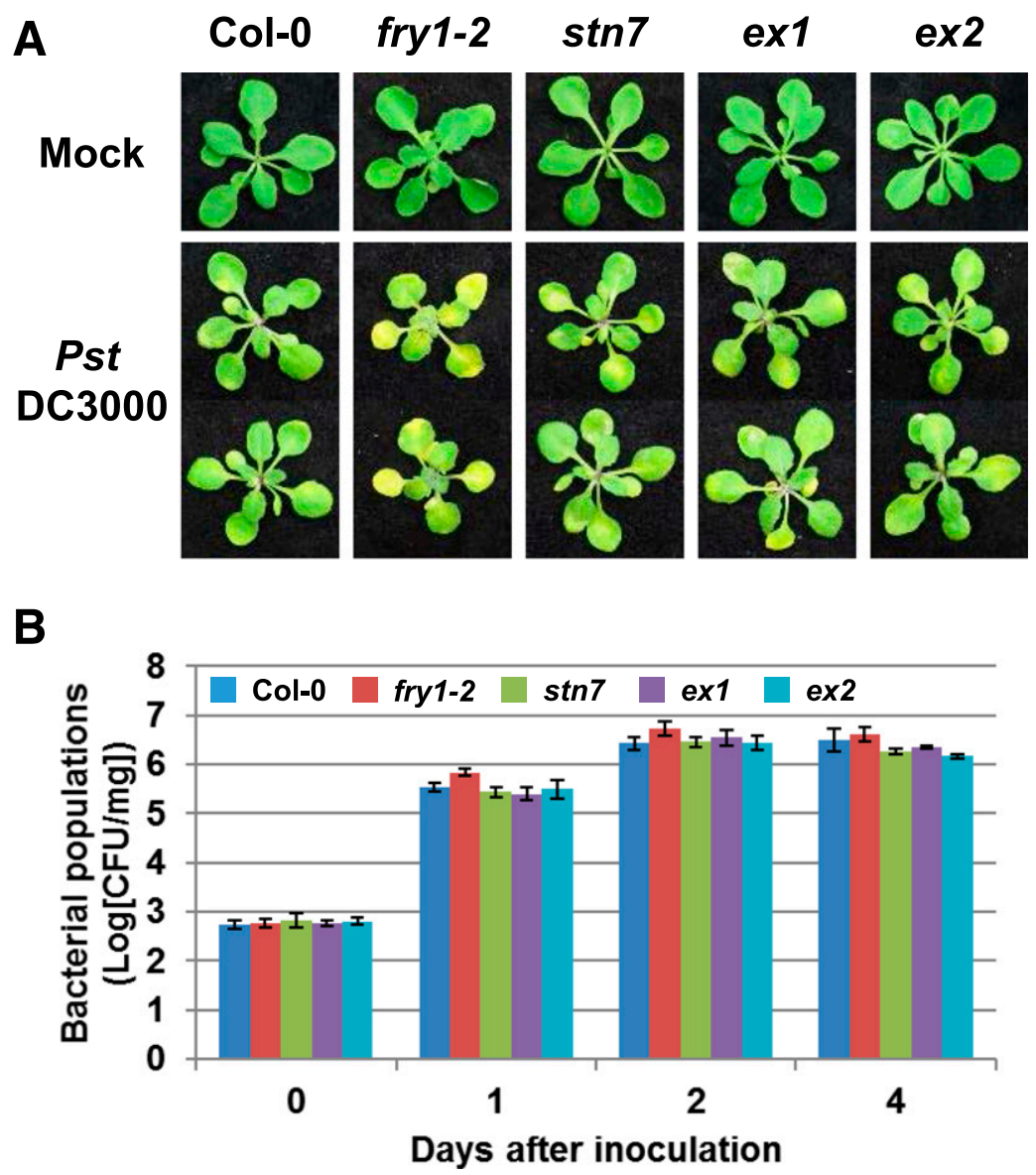

Fig. 1. A flood-inoculation assay for the analysis of the chloroplast retrograde signal pathways. A, Disease phenotype of two-week-old Arabidopsis wild type (Col-0), fry1-2, stn7 (stn7 protein kinase), ex1 (executer1), and ex2 mutant plants were flood-inoculated with pathogenic Pseudomonas syringae pv. tomato DC3000 (Pst DC3000) at the concentration of $5 \times 10^{6} \mathrm{CFU} / \mathrm{ml}$. The photographs were taken at 3 days postinoculation (dpi). B, Bacterial population dynamics in the Arabidopsis wild type (Col-0), fryl-2, stn7, ex1, and ex2 plants flood-inoculated with DC 3000 at $5 \times 10^{6} \mathrm{CFU} / \mathrm{ml}$. The bacterial populations were obtained by surface-sterilizing the inoculated leaves, grinding them, and then, plating dilutions to selective media at 0 , 1 , 2, and 4 dpi. Vertical bars indicate the standard errors for three independent experiments. 
the global change of sulfur metabolism in the fryl-2 and al $x 8$ mutants along with the wild type (Col-0). Both fryl-2 and al $x 8$ mutants were grown on MS plates, were flood-inoculated with DC3000 $\left(5 \times 10^{6} \mathrm{CFU} / \mathrm{ml}\right)$ or were drop-inoculated with EC1 (optical density at $600 \mathrm{~nm}\left[\mathrm{OD}_{600}\right]=0.001$ ), and the samples were fixed at 12,24 , and $48 \mathrm{~h}$ postinoculation with pathogens for metabolomics analyses. No significant differences were observed in the accumulation of sulfur-containing amino acids (cysteine

A
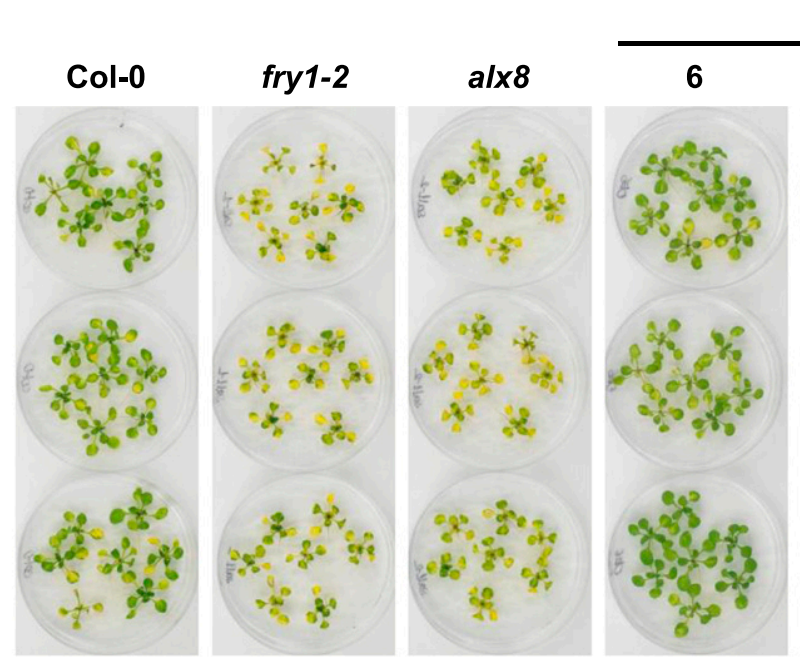

SAL1 overexpress

B

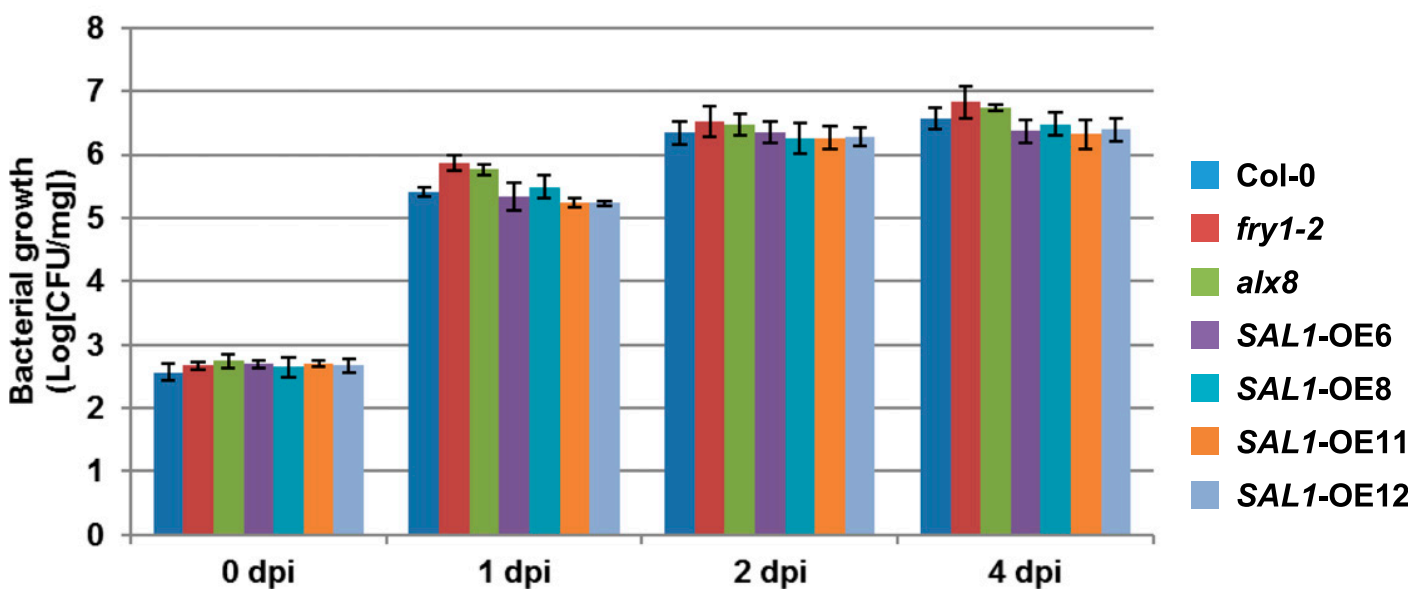

C

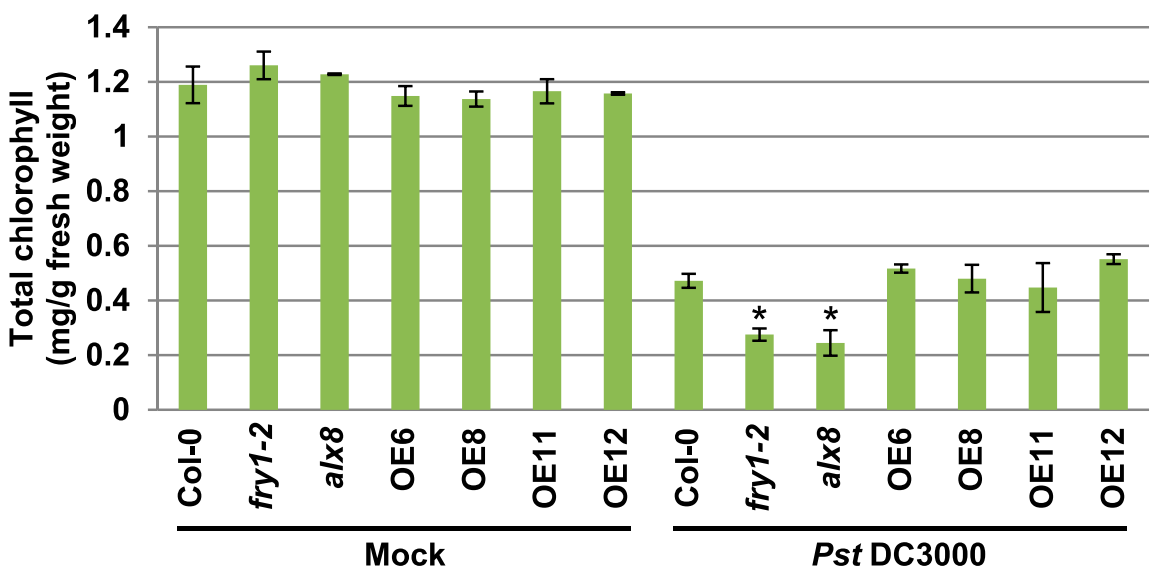

Fig. 2. A flood-inoculation assay for the analysis of the chloroplast SAL1-PAP retrograde signal pathway. A, Disease phenotype of the Arabidopsis wild type (Col-0), sal1 mutants (fry1-2 and alx8), and overexpression lines (SAL1-OE6, SAL1-OE8, SAL1-OE11, and SAL1-OE12) flood-inoculated with pathogenic Pseudomonas syringae pv. tomato DC3000 at the concentration of $5 \times 10^{6} \mathrm{CFU} / \mathrm{ml}$. Photographs were taken at 3 days postinoculation (dpi). B, Bacterial population dynamics in the Arabidopsis wild type (Col-0), sall mutants, and SAL1 overexpression lines flood-inoculated with DC 3000 at $5 \times 10^{6} \mathrm{CFU} / \mathrm{ml}$. The bacterial populations were obtained at $0,1,2$, and 4 dpi. Vertical bars indicate the standard errors for three independent experiments. $\mathbf{C}$, Total chlorophylls in the Arabidopsis wild type (Col-0), sall mutants, and SAL1 overexpression lines treated with water as a mock control (mock) or flood-inoculated with DC3000. Chlorophyll content was estimated at 3 dpi. Error bars indicate standard errors for three independent experiments. Asterisks indicate a significant difference from the wild-type Col-0 in a $t$ test $(P<0.05)$. 
and methionine) and glutathione (Supplementary Fig. S2). In addition, consistent with previous studies (Estavillo et al. 2011), high accumulation of PAP was observed in the fryl-2 and al 88 mutants. Moreover, inoculation with pathogens, including DC3000 and EC1, did not affect the metabolic profiles of PAP as well as the sulfur-containing amino acids.

Glucosinolates have been shown to play a critical role in the plant immune system, especially in nonhost resistance (Fan and Doerner 2012; Fan et al. 2011; Hiruma et al. 2010). We next asked whether the metabolic profiles of glucosinolates could be affected in the fry $1-2$ and al $x 8$ mutants during pathogen infection. Glucosinolate profiles revealed that the accumulation of aliphatic glucosinolates, including thio- and sulfinyl-glucosinolates, was reduced in the fryl and alx 8 mutants compared with the wildtype Col-0 (Supplementary Figs. S3 and S4). Interestingly, the accumulation of aliphatic glucosinolates, such as 5methylthiopentyl-glucosinolate (5MTP), 6-methylthiohexylglucosinolate (6MTH), 7-methylthioheptyl-glucosinolate (7MTH), 8-methylthiooctyl-glucosinolate (8MTO), 3-methylsulfinylpropylglucosinolate (3MSOP), 4-methylsulfinylbutyl-glucosinolate (4MSOB), 5-methylsulfinylpentyl-glucosinolate (5MSOP), 6-methylsulfinylhexyl-glucosinolate (6MSOH), 7-methylsulfinylheptylglucosinolate $(7 \mathrm{MSOH})$, and 8-methylsulfinyloctyl-glucosinolate (8MSOO), were clearly induced in both Col- 0 and the mutants by inoculation with the hemibiotrophic pathogen DC3000 but not by the necrotrophic pathogen EC1, suggesting that aliphatic glucosinolates may play a role in interaction against DC3000, especially those involved in disease symptom development.

We next investigated the metabolic profiles of indole glucosinolates in response to pathogens. Contrary to the metabolic profiles of aliphatic glucosinolates, a lower level of indolyl-3methyl glucosinolate (I3M) was observed in the wild-type Col-0 plants compared with the fryl-2 and alx8 mutants (Fig. 5A). However, no significant differences were observed in the accumulation of other indole glucosinolates, including 1-methoxyindol3-ylmethyl-glucosinolate $(1 \mathrm{MOI} 3 \mathrm{M})$ and $4 \mathrm{MOI} 3 \mathrm{M}$, between the wild-type Col-0 plants and the fryl-2 and al $x 8$ mutants (Figs. 5B and C). Furthermore, the accumulation of I3M and $4 \mathrm{MOI} 3 \mathrm{M}$ was induced to a higher extent by the inoculation with DC3000 in the wildtype Col- 0 plants when compared with fryl-2 and al $x 8$ mutants (Figs. $5 \mathrm{~B}$ and $\mathrm{C}$ ). Reduced induction of these compounds in fry $1-2$ and $a l x 8$ mutants upon inoculation with DC3000 may have contributed to increased disease symptoms and compromised ETI as shown earlier.

\section{SAL1-PAP chloroplast retrograde signaling mutants are compromised in the $\mathrm{SA}$ - and $\mathrm{JA}$-mediated signaling pathways.}

The SA- and JA-mediated signaling pathways that lead to plant immunity against invading pathogens have been extensively studied (Pieterse et al. 2012; Robert-Seilaniantz et al. 2011). In general, the SA-mediated signaling pathway is implicated in the regulation of defense responses against biotrophic and hemibiotrophic pathogens, while the JA pathway is associated with defense responses against necrotrophic pathogens (Pieterse et al. 2012; Robert-Seilaniantz et al. 2011). Since the fry $1-2$ and al $x 8$ mutants displayed enhanced susceptibility not only to a hemibiotrophic pathogen, DC3000, but also to a necrotrophic pathogen, EC1, we next assessed the activities of the SA- and JA-mediated signaling pathways, by investigating the accumulation of multiple phytohormones such as SA, ABA,
A

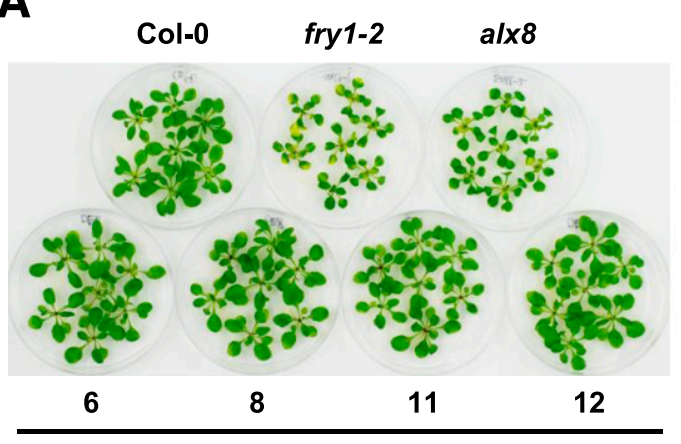

SAL1 overexpress

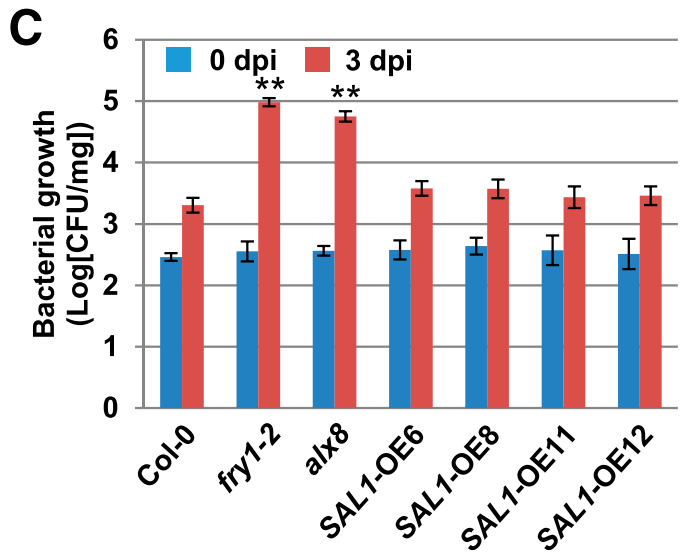

B

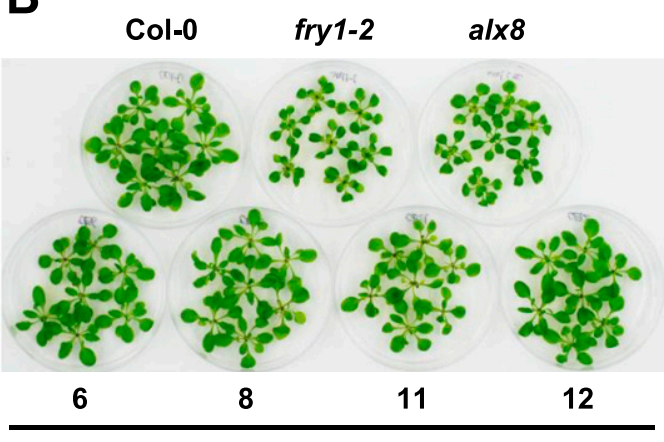

SAL1 overexpress

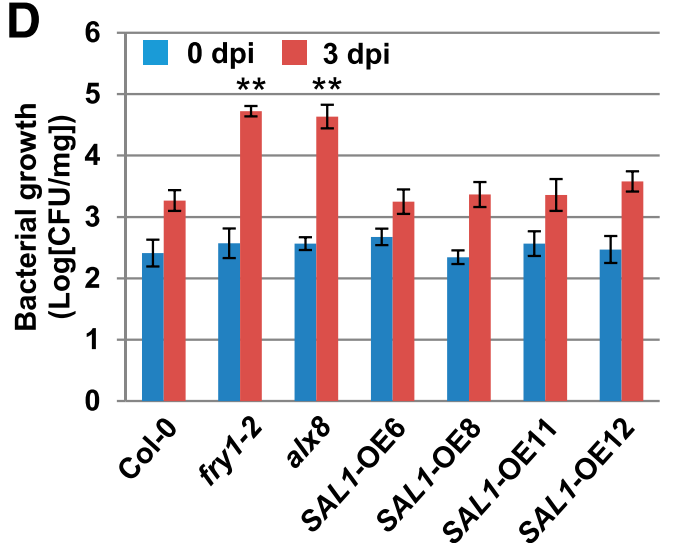

Fig. 3. A flood-inoculation assay for the analysis of effector-triggered immunity in the chloroplast SAL1-PAP retrograde signal pathway. A, Response of the Arabidopsis wild type (Col-0), sal1 mutants (fry1-2 and alx8), and overexpression lines (SAL1-OE6, SAL1-OE8, SAL1-OE11, and SAL1-OE12) floodinoculated with avirulent Pseudomonas syringae pv. tomato DC 3000 carrying AvrRpt 2 or B, AvrRpml at the concentration of $5 \times 10^{6} \mathrm{CFU} / \mathrm{ml}$. The photographs were taken at 3 days postinoculation (dpi). C, Bacterial population dynamics in the Arabidopsis wild type (Col-0), sal1 mutants, and SAL1 overexpression lines flood-inoculated with DC3000 expressing AvrRpt2 or D, AvrRpm1 at $5 \times 10^{6} \mathrm{CFU} / \mathrm{ml}$. The bacterial populations were obtained at 0 and 3 dpi. Error bars indicate standard errors for three independent experiments. Asterisks indicate a significant difference from the wild-type Col-0 in a $t$ test $(P<0.01)$. 
$\mathrm{JA}$, and JA-isoleucine (JA-Ile), and the expression profiles of the SA- and JA-responsive genes in the SAL1-PAP chloroplast retrograde signaling mutants.

Two-week-old Arabidopsis plants, including the wild-type Col-0, fry 1-2, and alx 8 mutants were grown on MS plates and were inoculated with EC1, and the samples, which were fixed at 12 and $24 \mathrm{~h}$ after inoculation, were then utilized for the quantification of multiple phytohormones by liquid chromatography (LC)-mass spectrometry analysis. Interestingly, a lower level of SA accumulation was observed in the fry $1-2$ and al $x 8$ mutant plants compared with Col-0 at the 0 timepoint (Fig. 6A), whereas no significant differences were observed in the accumulation of ABA, JA, and JA-Ile between the wild-type Col-0 and the SAL1-PAP chloroplast retrograde signaling mutants, with the exception of the $a l x 8$ mutant for JA-Ile (Fig. 6B, C, and D), indicating that the SAL1-PAP chloroplast retrograde signaling pathway may regulate SA biosynthesis. A higher level of JA and JA-Ile accumulation was observed in the fryl-2 and alx8 mutants in response to inoculation with EC1, as compared with the wild-type Col-0 (Figs. 6C and D), whereas a lower level of SA accumulation was observed in the fry $1-2$ and al $x 8$ mutants at $24 \mathrm{~h}$ after inoculation with EC1 (Fig. 6A).

We next investigated the expression profiles of $I C S 1, P R I$, $O P R 3$, and $P D F 1.2$ in response to SA or methyl jasmonic acid
(MeJA). Two-week-old Arabidopsis plants, including the wildtype Col-0, fry 1 and al $x 8$ mutants, and SAL1-overexpression plants, were grown on MS plates and were treated with water as a control (mock), $100 \mu \mathrm{M}$ of SA, or $500 \mu \mathrm{M}$ of MeJA and total RNA was then isolated from samples fixed at 6,12 , and $24 \mathrm{~h}$ after treatment. The expression of ICSI and PRI was induced by the treatment with SA in wild-type Col-0, the fry 1 and al $x 8$ mutants, and SAL1-overexpression plants (Fig. 7A and B). However, lower levels of the ICSI and PRI transcripts were observed in the fryl and alx 8 mutant plants compared with the wild-type Col-0 and SAL1-overexpression plants (Fig. 7A and B). In addition, the expression of a JA-responsive gene, $O P R 3$, was clearly induced in response to MeJA in all the lines tested (Fig. 7C). Surprisingly, MeJA treatment activated the expression of PDF1.2 in the wild-type Col-0 and SAL1-overexpression plants but not in the fryl and alx 8 mutants (Fig. 7D). Taken together, these results indicate that the fry 1 and al 88 mutant plants are partially compromised in the SA- and JA-mediated signaling pathways.

\section{DISCUSSION}

In this study, we conducted a functional analysis of the chloroplast retrograde signaling pathways in the plant immune system

A

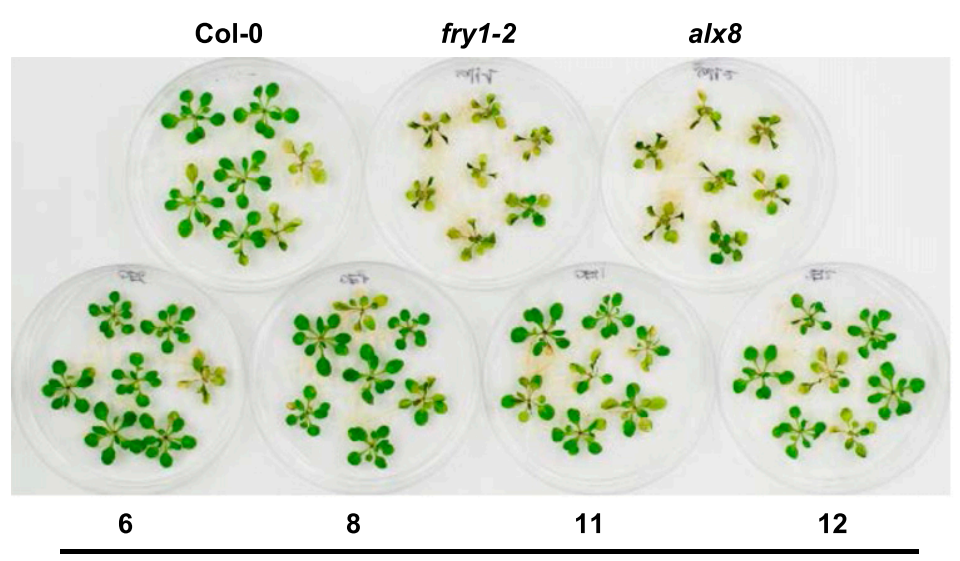

SAL1 overexpress

B

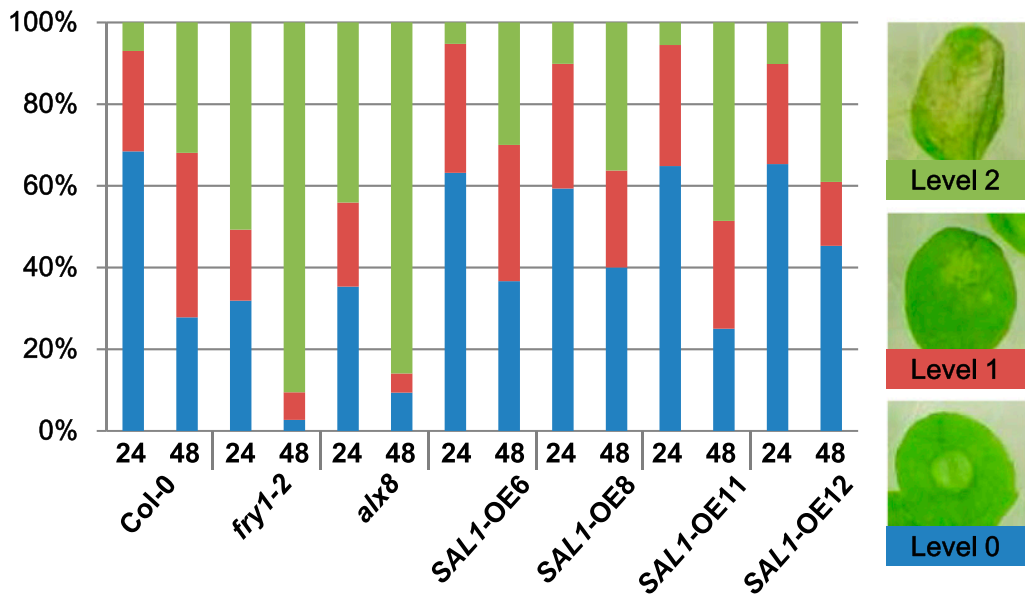

Fig. 4. An inoculation assay for the analysis of the chloroplast retrograde signal pathways in response to a necrotrophic bacterial pathogen. A, Disease phenotype of the Arabidopsis wild type (Col-0), sal1 mutants (fry1-2 and alx8), and overexpression lines (SAL1-OE6, SAL1-OE8, SAL1-OE11, and SAL1OE12) inoculated with Pectobacterium carotovorum subsp. carotovorum EC1. Arabidopsis leaves were drop-inoculated with strain EC1 at an optical density at $600 \mathrm{~nm}$ of 0.001 . The photographs were taken at 2 days postinoculation. B, Evaluation of the disease symptoms, at 24 and $48 \mathrm{~h}$, caused by EC1 inoculation. Level 0 indicates no symptoms, level 1 indicates disease symptoms restricted to within the inoculated region, and level 2 indicates disease symptoms outside of the inoculated region. At least 100 inoculation spots were evaluated for disease severity. 
and found that the SAL-PAP signaling pathway plays an important role in immune responses. Furthermore, we confirmed that sal1 mutant plants, including fry 1 and alx 8 , were susceptible not only to an avirulent hemibiotrophic pathogen, DC3000 (containing AvrRpml or AvrRpt2), but were also hypersusceptible to a necrotrophic pathogen, EC1, when compared with wild-type Col-0 plants (Figs. 1, 2, 3, and 4). In general, biotrophic and hemibiotrophic pathogens that depend entirely or partly on living host cells for their nutrient supply have been shown to induce SAmediated defense responses, whereas necrotrophic pathogens that utilize the nutrients from dead cells have been shown to be the primary activators of JA-mediated defense responses (Glazebrook 2005; Pieterse et al. 2012; Robert-Seilaniantz et al. 2011). Our study based on phytohormone analyses and expression profiles revealed that the sall mutant plants (fryl and alx 8 ) are compromised in the SA-mediated signaling pathway, resulting in enhanced susceptibility to an avirulent pathogen, DC3000 carrying either AvrRpt2 or AvrRpm1. However, enhanced disease symptoms in sall mutant plants inoculated with DC3000 were much more severe than in plants inoculated with DC3000 carrying either

A
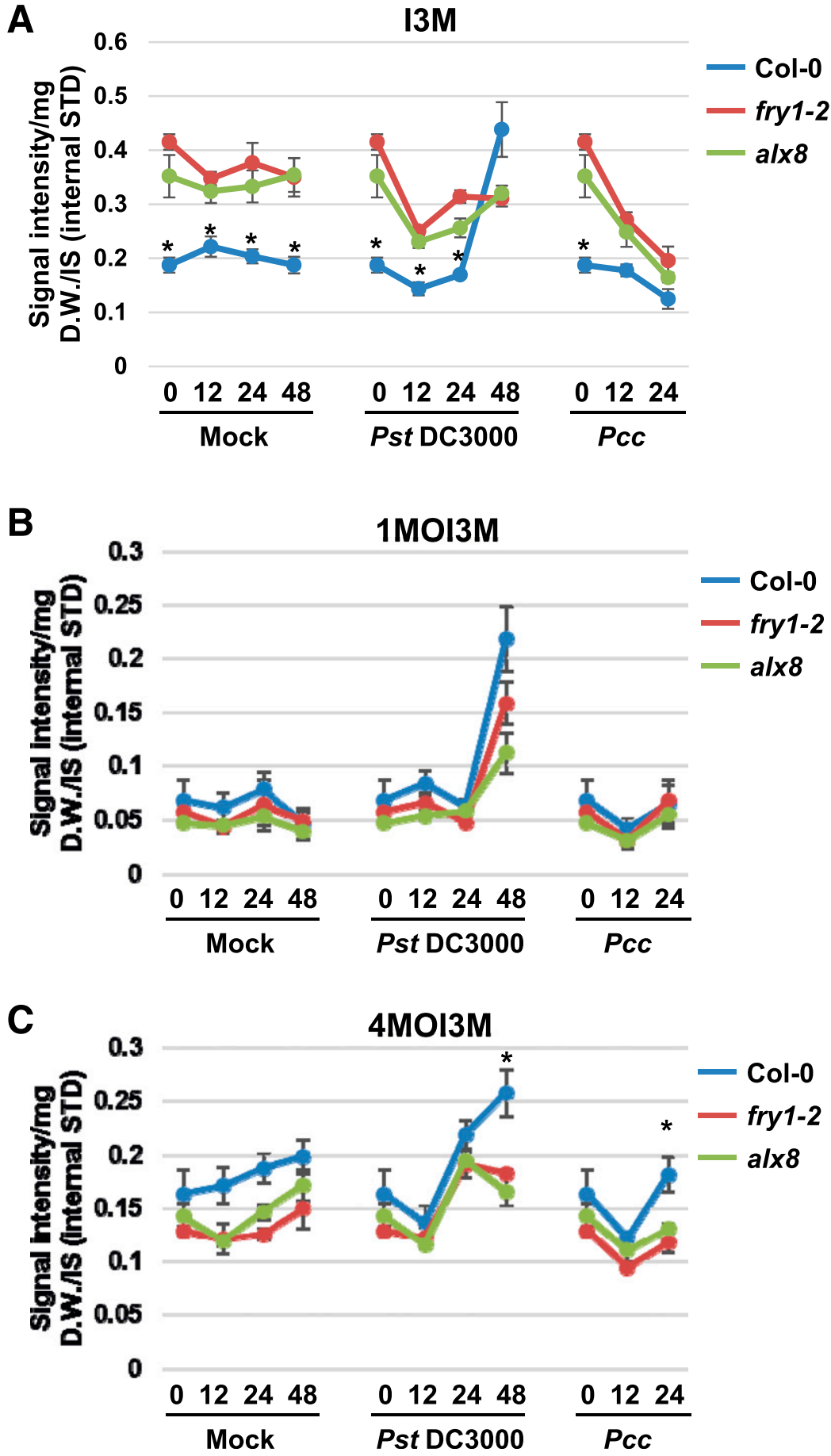

Fig. 5. A, A global change of indole-glucosinolates metabolism including I3M, B, 1MOI3M, and C, 4MOI3M in the Arabidopsis wild type (Col-0) and sall mutants (fryl-2 and alx 8) in response to pathogens. Two-week-old Col-0 and the sall mutants were treated with water as a mock control (Mock) or inoculated with Pseudomonas syringae pv. tomato DC3000 (Pst DC3000) for 12, 24, and 48 h or Pectobacterium carotovorum subsp. carotovorum EC1 (Pcc) for 12 and $24 \mathrm{~h}$. Error bars indicate standard errors for four independent experiments. Asterisks indicate a significant difference between the wild-type Col-0 and sall mutants in a $t$ test $(*=P<0.05)$. 
AvrRpt 2 or AvrRpm1, suggesting that sall mutants were not fully compromised in ETI (Figs. 2 and 3).

In addition, sall mutants had less endogenous SA when compared with wild-type Col-0 (Fig. 6). Likewise, the sot 12 (sulphotransferase 12) mutant related to the metabolic pathway of sulfur assimilation was also shown to have reduced endogenous SA accumulation resulting in enhanced susceptibility to DC3000 carrying AvrRps4 (Baek et al. 2010). The functional analysis of the Arabidopsis sot 12 mutant and the SOT12 overexpressor demonstrated that SOT12 could regulate endogenous SA levels by transferring sulfate from PAPS to the hydroxyl moiety of SA (Baek et al. 2010). In this study, we demonstrated that sall mutants accumulated high levels of PAP. Interestingly, PAP was reported to inhibit the activity of SOTs (Klaassen and Boles 1997). Therefore, it is tempting to speculate that PAP accumulation in sall mutants could reduce SA levels by inhibiting SOT12. Our results suggest that the SAL1-PAP chloroplast retrograde signaling pathway may have an affect upstream of SA biosynthesis. The role of the SA-mediated signaling pathway in plant resistance against DC3000 is well-understood. SA-deficient $N a h G$ and sid2 Arabidopsis plants show high susceptibility to DC3000 (Brooks et al. 2005). Over the last decade, it has become obvious that the SA- and JA-mediated signaling pathways are mutually antagonistic (Pieterse et al. 2012; Robert-Seilaniantz et al. 2011). Crosstalk between SA and JA possibly reduces the fitness costs of inappropriate defense responses and enables the plant to fine-tune the induction of plant defenses in response to different types of invading pathogens (Pieterse et al. 2012;
Robert-Seilaniantz et al. 2011). It is well-known that DC3000 produces nonproteinaceous effectors, including the phytotoxin COR (Bender et al. 1998). COR functions as a JA-Ile analog and can be recognized by the JA-Ile receptor complex COI1/JAZ, resulting in the activation of the JA pathway and concomitant suppression of the SA pathway, promoting the susceptibility of DC3000 (Brooks et al. 2005; Katsir et al. 2008; Uppalapati et al. 2007; Zhao et al. 2003). Our expression profiles demonstrated that the sall mutant plants (fryl and alx8) were compromised in the SA- and JA-mediated signaling pathways (Fig. 7). Interestingly, the sall mutants have demonstrated resistance to drought stress by activating the expression of genes related to drought resistance through the $\mathrm{ABA}$-mediated signaling pathway (Wilson et al. 2009; Xiong et al. 2001). In addition to the mutually antagonistic interactions between SA and JA, crosstalks between either SA and ABA, JA and ABA, or both have been shown to function in the robust response of plants to different types of pathogens and herbivores (Robert-Seilaniantz et al. 2011). Taken together, it is tempting to speculate that the SAL1-PAP retrograde signaling pathway may function as a key regulator to fine-tune the signaling pathways between biotic and abiotic stresses in plants. Further identification of regulators that function in biotic and abiotic stresses and investigation of combinatorial stress responses in conjunction with the SAL1-PAP pathway are needed to understand plant stress responses.

Glucosinolate profiles revealed a lower level of aliphatic glucosinolate accumulation in the sall mutant plants (fryl-2 and alx8) compared with wild-type Col-0, and the accumulation of
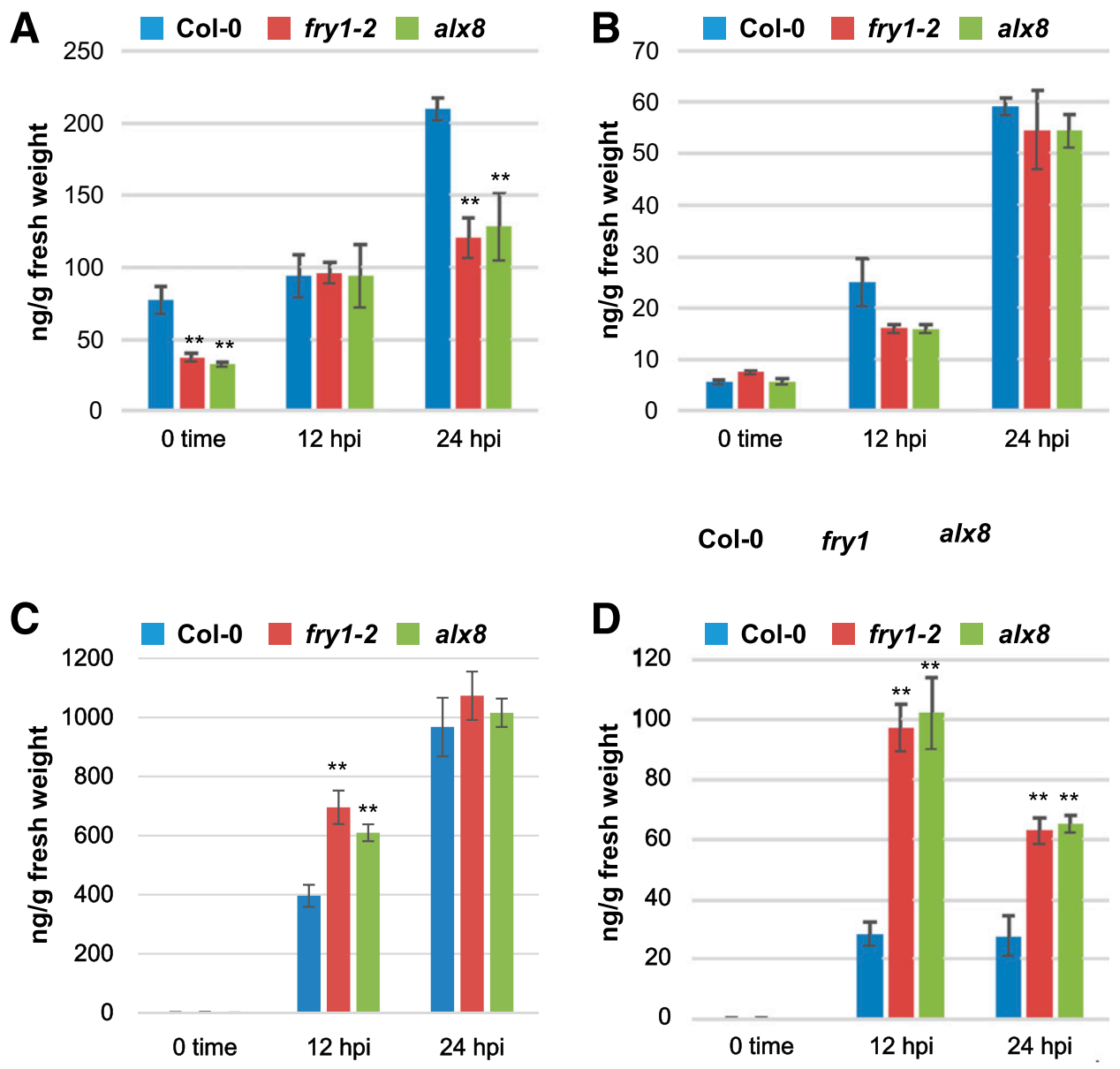

Fig. 6. A, Quantification of phytohormones including salicylic acid, B, abscisic acid, C, jasmonate, and D, jasmonate-isoleucine in the Arabidopsis wild type (Col-0) and sall mutant (fryl-2 and alx8) plants inoculated with Pectobacterium carotovorum subsp. carotovorum EC1. Two-week-old Arabidopsis leaves were drop-inoculated with EC1 at an optical density at $600 \mathrm{~nm}$ of 0.001 for 12 and $24 \mathrm{~h}$ and were then used for phytohormone quantification. Error bars indicate standard errors for five biological replicates. Asterisks indicate a significant difference from the wild-type Col-0 in a $t$ test $(* *=P<0.01)$. 
aliphatic glucosinolates was induced during DC3000 infection in Col-0 plants but to a lesser extent in sall mutant plants. Our glucosinolate profiles also demonstrated that the accumulation of indole glucosinolates upon DC300 inoculation was less in sall mutants when compared with wild-type Col-0 plants (Fig. 5). Glucosinolates have been shown to play a critical role in the plant immune system against pests and pathogens, indole glucosinolates, especially, have been reported to play an important role in the nonhost resistance of Arabidopsis against fungal pathogens (Bednarek et al. 2009; Clay et al. 2009; Hiruma et al. 2013; Stotz et al. 2011). Furthermore, in Arabidopsis, nonhost resistancerelated PENETRATION genes (PEN1, PEN2, and PEN3), which are essential for penetration resistance against nonadapted biotrophic fungal pathogens, have been identified (Collins et al. 2003; Lipka et al. 2005; Stein et al. 2006). Functional analyses of PENs in nonhost resistance have demonstrated that PEN2 and PEN3 function together to produce and transport antifungal products derived from indole glucosinolates to infection sites (Lipka et al. 2005; Stein et al. 2006). Besides the antifungal activity in the compounds derived from indole glucosinolates, sulforaphane (4-methylsulfinylbutyl isothiocyanate), a natural compound derived from aliphatic glucosinolates, is known to have a function in nonhost resistance of Arabidopsis against nonhost bacterial pathogens such as $P$. syringae pv. tomato T1, $P$. syringae pv. tabaci, and $P$. syringae pv. glycinea (Andersson et al. 2015; Fan et al. 2011). Interestingly, Pseudomonas species, including
DC3000, have been reported to maintain multiple sax genes encoding the functional transporter to release these antibacterial compounds derived from aliphatic glucosinolates (Fan et al. 2011). In this study, we demonstrated the enhanced susceptibility of the sall mutant plants against avirulent pathogens such as DC3000 carrying AvrRpt2 or AvrRpm1, indicating that SAL1 may function in ETI (Fig. 3). ETI is known to trigger strong disease resistance by inducing basal defense reactions and activating programmed cell death (Cui et al. 2015). Although there is a good understanding of the signaling pathway leading to programmed cell death in ETI, not much is known about how plants inhibit bacterial growth during ETI. Further, there is increasing evidence for functional overlaps between ETI and nonhost resistance (Gill et al. 2015; Senthil-Kumar and Mysore 2013). Together, it is possible that antibacterial compounds derived from aliphatic glucosinolates may have a critical role not only in nonhost resistance but, also, in ETI, by inhibiting the bacterial growth. Therefore, further identification of antibacterial compounds that function in ETI and characterization of their modes of action are needed to understand plant immunity.

It has been shown that mutation of the $S A L 1$ gene affects a wide range of cellular processes including sulfur metabolism. Recent study demonstrated that the SAL1 functions as an oxidative sensor in the chloroplast, based on the mechanism by which chloroplast-derived ROS induces disulfide-bounded SAL1, resulting in decreased activity of SAL1 (Chan et al. 2016b). These
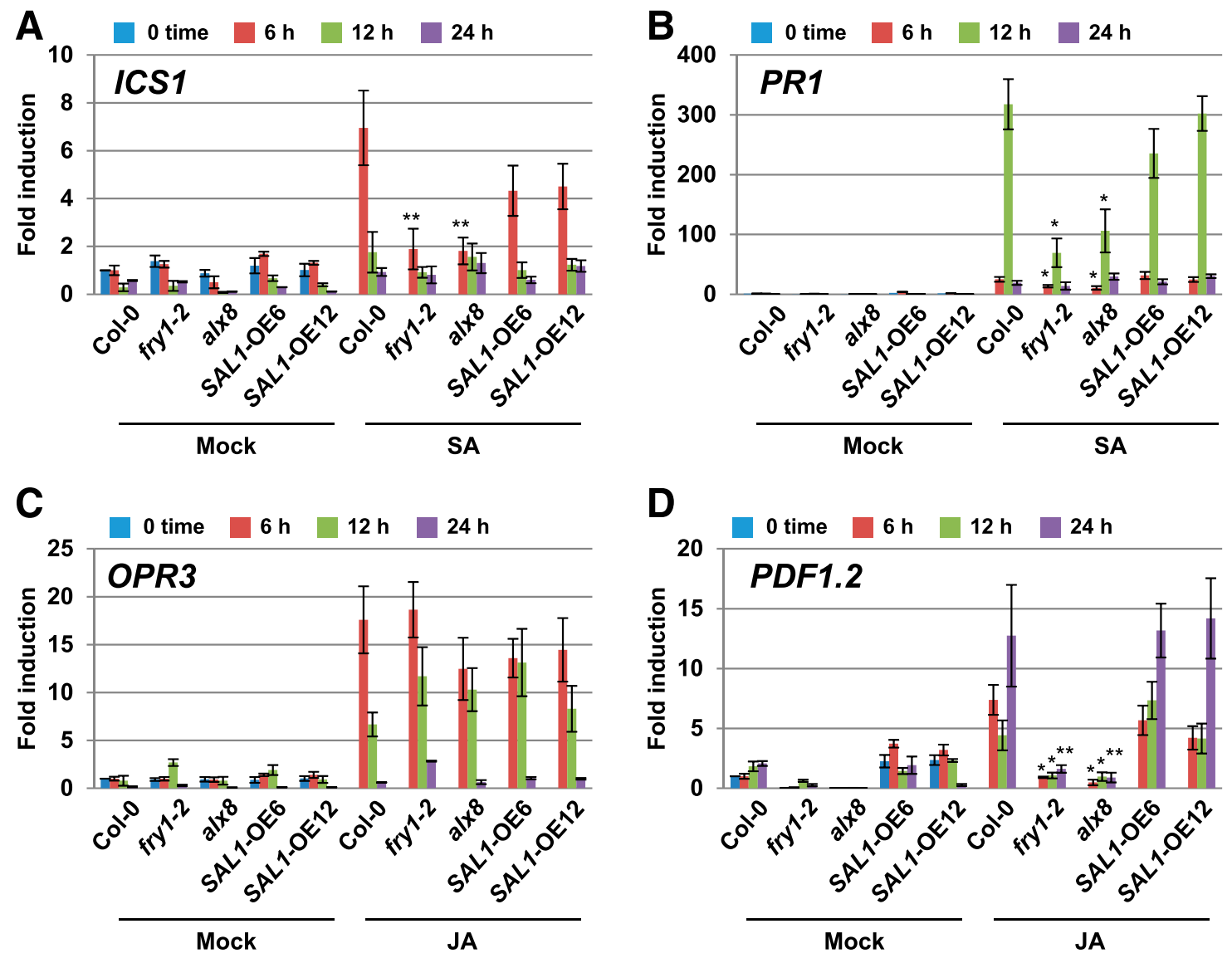

Fig. 7. Expression profiles of genes encoding proteins involved in salicylic acid (SA)- and jasmonic acid (JA)-mediated signaling pathways. A, The expression profiles of the SA-pathway genes including ISOCHORISMATE SYNTHASE 1 (ICS1) and B, PATHOGENESIS-RELATED PROTEIN 1 (PR1) at 6, 12, and 24 h after treatment with SA. C, The expression profiles of the JA-pathway genes including 12-OXOPHYTODIENOATE REDUCTASE 3 (OPR3) and D, PLANT DEFENSIN 1.2 (PDF1.2) at 6, 12, and $24 \mathrm{~h}$ after treatment with methyl jasmonate (MeJA). Two-week-old Arabidopsis wild type (Col-0), sall mutants (fryl-2 and $a l x 8$ ), and overexpression lines (SAL1-OE6 and SAL1-OE12) were treated with water as a mock control (Mock), SA (1 mM), or MeJA (100 mM) for 6, 12, and $24 \mathrm{~h}$. The expression of genes was evaluated by quantitative revesrse transcriptio-polymerase chain reaction with gene-specific primer sets. The values represent the relative induction compared with the expression of Ubiquitin 1 (UBQ1). Error bars indicate standard errors for three biological replicates. Asterisks indicate a significant difference from the wild-type Col-0 in a $t$ test $(*=P<0.05, * *=P<0.01)$. 
results suggest that chloroplast ROS could induce PAP accumulation to regulate the expression of plastid redox-associated nuclear genes through retrograde signaling. We previously demonstrated that COR produced from DC3000 targeted chloroplast ROS homeostasis, resulting in ROS burst (Ishiga et al. 2009, 2012). In this study, we showed that the sall mutants were more susceptible to pathogens (Figs. 2, 3, and 4) together with high levels of PAP accumulation. Thus, it is possible that pathogens, including DC3000, regulate PAP levels for their virulence by targeting chloroplast ROS homeostasis or expression of SAL1. Therefore, further identification of virulence factors that regulate PAP levels and characterization of their modes of action are needed to understand the virulence mechanism of pathogens.

\section{MATERIALS AND METHODS}

\section{Plant materials and growth conditions.}

Arabidopsis thaliana ecotype Colombia (Col-0) was used as a wild-type plant in this study. The mutant lines for sall (At5g63980) including fryl-2 (SALK_151367) and alx8 (CS66977) and chloroplast retrograde mutants including stn7 (SALK_073254C), exI (SALK_002088C), and ex2 (SALK_121009C) were obtained from the Arabidopsis Biological Resource Center stock center (Columbus, OH, U.S.A.). Arabidopsis seeds were germinated and maintained on $1 / 2$ MS medium ( $0.3 \%$ phytagel) with Gamborg vitamins (Sigma-Aldrich, St. Louis). Arabidopsis plants were incubated at $24^{\circ} \mathrm{C}$ with a light intensity of $200 \mu \mathrm{E} \mathrm{m}^{-2} \mathrm{~s}^{-1}$ and a 12-h light and 12-h dark photoperiod, and the seedlings, at two weeks postgermination, were used for pathogen assays.

\section{Cloning of $S A L 1$, vector construction, and plant transformation.}

To clone the coding region of $S A L 1$, the gene was amplified by polymerase chain reaction (PCR) with the forward primer 5'-ATGATGTCTATAAATTGTTTTCGA-3' and the reverse primer 5' -TCAGAGAGCTGAAGCTTTCTCTTG-3'. The DNA fragment was amplified with Platinum Pfx DNA polymerase (Life Technologies, Waltham, MA, U.S.A.), and then, deoxyadenine was added to the $3^{\prime}$ end of the PCR product with Ex Taq DNA polymerase (TaKaRa, Shiga, Japan). The resultant DNA was cloned into a pCR8/GW/TOPO TA cloning vector (Life Technologies), according to the manufacturer's instructions, and the DNA insertion was verified by restriction enzymes and sequence analyses. The SAL1 cDNA was inserted into the binary transformation plasmid pMDC32 (Curtis and Grossniklaus 2003) using Gateway LR clonase enzyme mix (Life Technologies). The resultant plasmid, possessing a $2 \times 35 \mathrm{~S}$ promoter governing the SAL1 gene, was introduced into Agrobacterium tumefaciens LBA4404.

Arabidopsis wild-type Col-0 was transformed with Agrobacterium tumefaciens by the floral inoculation method (Clough and Bent 1998). Seeds collected from the transformed plants were sterilized with $2 \%$ sodium hypochlorite and $0.01 \%$ Tween 20 (Sigma-Aldrich) for $15 \mathrm{~min}$ and were washed three times with sterilized water. The sterilized seeds were placed on MS agar medium containing $25 \mu \mathrm{g}$ of hygromycin B per milliliter (SigmaAldrich) and $50 \mu \mathrm{g}$ of cefotaxime per milliliter (Sigma-Aldrich). Transgenic T1 seedlings were selected on MS plates; after 3 weeks of growth, the existence of the transgene was confirmed by PCR analysis, and T3 homozygous lines were used for further experiments.

\section{Bacterial strains and growth conditions.}

P. syringae pv. tomato DC3000 and Pectobacterium carotovorum subsp. carotovorum EC1 were used as hemibiotrophic and necrotrophic bacterial pathogens on Arabidopsis, respectively. DC3000 carrying AvrRpt 2 or AvrRpml was used as an avirulent pathogen. DC3000 and EC1 were grown at $28^{\circ} \mathrm{C}$ on mannitol-glutamate (MG) and lysogeny broth medium, respectively. DC3000 carrying AvrRpt2 or AvrRpml was grown at $28^{\circ} \mathrm{C}$ on MG media containing $50 \mu \mathrm{g}$ of kanamycin per milliliter. Prior to inoculation, the bacteria were suspended in sterile distilled $\mathrm{H}_{2} \mathrm{O}$ and bacterial cell densities $\left(\mathrm{OD}_{600}\right)$ were measured, using a JASCO V-730 spectrophotometer (Jasco, Tokyo).

\section{Bacterial inoculation.}

A flood-inoculation method was used to observe disease symptoms of DC3000 in Arabidopsis, as described previously (Ishiga et al. 2011). Briefly, 30 to $40 \mathrm{ml}$ of bacterial suspension made in sterile distilled $\mathrm{H}_{2} \mathrm{O}$ containing $0.025 \%$ Silwet L-77 (OSI Specialties Inc., Danbury, CT, U.S.A.) was dispensed into the plate containing 2-week-old Arabidopsis plants to perform uniform inoculation, and the plates were incubated for 2 to $3 \mathrm{~min}$ at room temperature. After the bacterial suspension was removed by decantation, plates containing inoculated plants were sealed with surgical tape and were incubated at $24^{\circ} \mathrm{C}$, with a light intensity of $200 \mu \mathrm{E} \mathrm{m}^{-2} \mathrm{~s}^{-1}$ and a 12-h light and 12-h dark photoperiod.

To determine the bacterial growth in Arabidopsis leaves, the internal bacterial population was measured at several timepoints. For the determination of internal bacterial growth, inoculated plants were collected and the total weight of the inoculated plants was measured. After measurement of the weight, the plants were surface-sterilized with $5 \% \mathrm{H}_{2} \mathrm{O}_{2}$ for $3 \mathrm{~min}$. After washing three times with sterile distilled water, plants were homogenized in sterile distilled water and the solution was subject to serial dilution. The diluted samples were plated onto MG medium. Two days after plating of the diluted samples, the bacterial CFU were counted, using proper diluted samples. The CFU was normalized as CFU per milligram, using the total weights of the inoculated plants. The bacterial populations were evaluated in three independent experiments.

EC1 was suspended in $0.9 \% \mathrm{NaCl}$ and was adjusted to an $\mathrm{OD}_{600}$ of 0.001 . To observe the disease symptoms on Arabidopsis leaves, $10 \mu \mathrm{l}$ of bacterial suspension was dropped onto the leaves as described (Higashi et al. 2008). After 24 and $48 \mathrm{~h}$ of incubation, the disease symptoms were scored according to the disease index.

\section{Chlorophyll content measurement.}

The chlorophyll content of the Arabidopsis plants was measured according to a previous study (Ishiga et al. 2009). Briefly, four plants were either treated with water as a control (mock) or inoculated with DC3000 and were incubated for 3 days under light $\left(200 \mu \mathrm{mol} \mathrm{m} \mathrm{s}^{-2}, 12 \mathrm{~h}\right.$ of light and $12 \mathrm{~h}$ of dark $)$ at $24^{\circ} \mathrm{C}$. Arabidopsis plants were then macerated in liquid nitrogen, were placed in $6 \mathrm{ml}$ of acetone, and were incubated at $4^{\circ} \mathrm{C}$ in the dark for $12 \mathrm{~h}$. Aliquots of total chlorophyll dissolved in acetone were mixed with hexane and $10 \mathrm{mM} \mathrm{KOH}$ at a ratio of 4:6:1 ( $\mathrm{vol} / \mathrm{vol} / \mathrm{vol})$. Chlorophylls $a$ and $b$ were quantified using a JASCO V-730 spectrophotometer and a formula described by a previous study (Arnon 1949).

\section{Metabolite extraction and measurement.}

Thiols, amino acids, and secondary metabolites were measured in the aqueous-methanol phase from chloroform/methanol extracts, as described previously (Watanabe et al. 2013). Approximately $4 \mathrm{mg}$ of freeze-dried finely ground plant material was homogenized in $700 \mu \mathrm{l}$ of methanol, and then, $300 \mu \mathrm{l}$ of chloroform was added. The polar fraction was prepared by liquid partitioning into $750 \mu \mathrm{l}$ of ultrapure water. After centrifugation, aliquots of $200 \mu \mathrm{l}$ of polar fractions were vacuum-dried. For measurement of thiol contents, the dried polar phase was resuspended in $60 \mu \mathrm{l}$ of $0.1 \mathrm{M} \mathrm{HCl}$. Thiols were measured by a combination of monobromobimane fluorescent labeling and 
high-pressure LC (HPLC) (Anderson 1985; Fahey and Newton 1987).

Measurement of secondary metabolites was performed by LC/electrospray ionization (ESI)-mass spectrometry. The dried polar phase was resuspended in $100 \mu \mathrm{l}$ of $80 \%$ ( $\mathrm{vol} / \mathrm{vol})$ methanol containing isovitexin $(5 \mu \mathrm{g} / \mathrm{ml})$ as an internal standard. Metabolite profiling by LC/ESI-mass spectrometry was performed as described previously (Tohge and Fernie 2010).

PAP was measured in the aqueous-methanol phase by specific derivatization of adenosine compounds with chloroacetaldehyde, as described previously (Bürstenbinder et al. 2007; Estavillo et al. 2011). The dried polar phase was resuspended in $7.5 \mu \mathrm{l}$ of $0.1 \mathrm{M} \mathrm{HCl}$. PAP was measured by a combination of chloroacetaldehyde fluorescent labeling and HPLC.

\section{Quantification of multiple phytohormones.}

Approximately $100 \mathrm{mg}$ of fresh weight of two-week-old Arabidopsis plants grown on MS plates were used for extraction. Extraction, purification, and quantification were performed as described (Tsukahara et al. 2015). Briefly, harvested samples were ground with liquid nitrogen. A mix of internal standard and extraction solvent $(1 \%$ acetic acid $[\mathrm{AcOH}], 80 \%$ acetonitrile $[\mathrm{MeCN}]$ ) was added to the powdered tissue, and the mixture was purified by Oasis HLB, MCX and WAX extraction cartridge (Waters Corp., Milford, MA, U.S.A.). In this way, only free SA was detected and SA beta-glucoside was not detected. Quantification was performed by an Agilent 6410 Triple Quad LC/MS (Agilent Technologies Inc., Santa Clara, CA, U.S.A.) equipped with a ZORBAX Eclipse XDB-C18 column (Agilent Technologies Inc.), using five independent samples for each genotype.

\section{Real-time quantitative reverse transcription (qRT)-PCR.}

Total RNA extraction and real-time qRT-PCR were done as described (Ishiga et al. 2013). Total RNA was extracted, using TRIzol RNA isolation reagents (Life Technologies) according to the manufacturer's protocol. Two micrograms of total RNA were treated with gDNA Eraser (TaKaRa) to eliminate genomic DNA, and the DNase-treated RNA was reverse transcribed using the PrimeScript RT reagent kit (TaKaRa). The cDNA (1:20) was then used for qRT-PCR, performed using the primers shown in Supplementary Table S1 with SYBR Premix Ex Taq II (TaKaRa) on a thermal cycler Dice real time system (TaKaRa). The Arabidopsis $U B Q 1$ gene was used as an internal control. Average cycle threshold values, calculated using the second derivative maximum method from triplicate samples, were used to determine the fold expression relative to the controls.

\section{ACKNOWLEDGMENTS}

This work was supported by the Noble Research Institute, LLC, in part by Program to Disseminate Tenure Tracking System, MEXT, Japan, Japan Advanced Plant Science Network, and the Max Planck Society.

\section{LITERATURE CITED}

Agerbirk, N., and Olsen, C. E. 2012. Glucosinolate structures in evolution. Phytochemistry 77:16-45.

Anderson, M. E. 1985. Determination of glutathione and glutathione disulfide in biological samples. Methods Enzymol. 113:548-555.

Andersson, M. X., Nilsson, A. K., Johansson, O. N., Boztaș, G., Adolfsson, L. E., Pinosa, F., Petit, C. G., Aronsson, H., Mackey, D., Tör, M., Hamberg, M., and Ellerström, M. 2015. Involvement of the electrophilic isothiocyanate sulforaphane in Arabidopsis local defense responses. Plant Physiol. 167:251-261.

Arnon, D. I. 1949. Copper enzymes in isolated chloroplasts. Polyphenoloxidase in Beta vulgaris. Plant Physiol. 24:1-15.

Baek, D., Pathange, P., Chung, J. S., Jiang, J., Gao, L., Oikawa, A., Hirai, M. Y., Saito, K., Pare, P. W., and Shi, H. 2010. A stress-inducible sulphotransferase sulphonates salicylic acid and confers pathogen resistance in Arabidopsis. Plant Cell Environ. 33:1383-1392.

Bednarek, P., Pislewska-Bednarek, M., Svatos, A., Schneider, B., Doubsky, J., Mansurova, M., Humphry, M., Consonni, C., Panstruga, R., SanchezVallet, A., Molina, A., and Schulze-Lefert, P. 2009. A glucosinolate metabolism pathway in living plant cells mediates broad-spectrum antifungal defense. Science 323:101-106.

Bender, C. L., Palmer, D. A., Peñaloza-Vázquez, A., Rangaswamy, V., and Ullrich, M. 1998. Biosynthesis and regulation of coronatine, a non-hostspecific phytotoxin produced by Pseudomonas syringae. Subcell. Biochem. 29:321-341.

Boatwright, J. L., and Pajerowska-Mukhtar, K. 2013. Salicylic acid: An old hormone up to new tricks. Mol. Plant Pathol. 14:623-634.

Brooks, D. M., Bender, C. L., and Kunkel, B. N. 2005. The Pseudomonas syringae phytotoxin coronatine promotes virulence by overcoming salicylic acid-dependent defences in Arabidopsis thaliana. Mol. Plant Pathol. 6:629-639.

Bruggeman, Q., Mazubert, C., Prunier, F., Lugan, R., Chan, K. X., Phua, S. Y., Pogson, B. J., Krieger-Liszkay, A., Delarue, M., Benhamed, M., Bergounioux, C., and Raynaud, C. 2016. Chloroplast activity and 3'phosphadenosine 5'phosphate signaling regulate programmed cell death in Arabidopsis. Plant Physiol. 170:1745-1756.

Bürstenbinder, K., Rzewuski, G., Wirtz, M., Hell, R., and Sauter, M. 2007. The role of methionine recycling for ethylene synthesis in Arabidopsis. Plant J. 49:238-249.

Chan, K. X., Mabbitt, P. D., Phua, S. Y., Mueller, J. W., Nisar, N., Gigolashvili, T., Stroeher, E., Grassl, J., Arlt, W., Estavillo, G. M., Jackson, C. J., and Pogson, B. J. 2016b. Sensing and signaling of oxidative stress in chloroplasts by inactivation of the SAL1 phosphoadenosine phosphatase. Proc. Natl. Acad. Sci. U.S.A. 113:E4567-E4576.

Chan, K. X., Phua, S. Y., Crisp, P., McQuinn, R., and Pogson, B. J. 2016 a. Learning the languages of the chloroplast: Retrograde signaling and beyond. Annu. Rev. Plant Biol. 67:25-53.

Chen, H., and Xiong, L. 2010. The bifunctional abiotic stress signalling regulator and endogenous RNA silencing suppressor FIERY1 is required for lateral root formation. Plant Cell Environ. 33:2180-2190.

Chi, W., Feng, P., Ma, J., and Zhang, L. 2015. Metabolites and chloroplast retrograde signaling. Curr. Opin. Plant Biol. 25:32-38.

Chi, W., Sun, X., and Zhang, L. 2013. Intracellular signaling from plastid to nucleus. Annu. Rev. Plant Biol. 64:559-582.

Ciuffetti, L. M., Manning, V. A., Pandelova, I., Betts, M. F., and Martinez, J. P. 2010. Host-selective toxins, Ptr ToxA and Ptr ToxB, as necrotrophic effectors in the Pyrenophora tritici-repentis-wheat interaction. New Phytol. 187:911-919.

Clay, N. K., Adio, A. M., Denoux, C., Jander, G., and Ausubel, F. M. 2009. Glucosinolate metabolites required for an Arabidopsis innate immune response. Science 323:95-101.

Clough, S. J., and Bent, A. F. 1998. Floral dip: A simplified method for Agrobacterium-mediated transformation of Arabidopsis thaliana. Plant J. 16:735-743.

Collins, N. C., Thordal-Christensen, H., Lipka, V., Bau, S., Kombrink, E., Qiu, J. L., Hückelhoven, R., Stein, M., Freialdenhoven, A., Somerville, S. C., and Schulze-Lefert, P. 2003. SNARE-protein-mediated disease resistance at the plant cell wall. Nature 425:973-977.

Cui, H., Tsuda, K., and Parker, J. E. 2015. Effector-triggered immunity: From pathogen perception to robust defense. Annu. Rev. Plant Biol. 66: 487-511.

Curtis, M. D., and Grossniklaus, U. 2003. A gateway cloning vector set for high-throughput functional analysis of genes in planta. Plant Physiol. 133:462-469.

Estavillo, G. M., Crisp, P. A., Pornsiriwong, W., Wirtz, M., Collinge, D., Carrie, C., Giraud, E., Whelan, J., David, P., Javot, H., Brearley, C., Hell, R., Marin, E., and Pogson, B. J. 2011. Evidence for a SAL1-PAP chloroplast retrograde pathway that functions in drought and high light signaling in Arabidopsis. Plant Cell 23:3992-4012.

Fahey, R. C., and Newton, G. L. 1987. Determination of low-molecularweight thiols using monobromobimane fluorescent labeling and highperformance liquid chromatography. Methods Enzymol. 143:85-96.

Fan, J., Crooks, C., Creissen, G., Hill, L., Fairhurst, S., Doerner, P., and Lamb, C. 2011. Pseudomonas sax genes overcome aliphatic isothiocyanatemediated non-host resistance in Arabidopsis. Science 331:1185-1188.

Fan, J., and Doerner, P. 2012. Genetic and molecular basis of nonhost disease resistance: Complex, yes; silver bullet, no. Curr. Opin. Plant Biol. 15:400-406.

Fu, Z. Q., and Dong, X. 2013. Systemic acquired resistance: Turning local infection into global defense. Annu. Rev. Plant Biol. 64:839-863.

Gill, U. S., Lee, S., and Mysore, K. S. 2015. Host versus nonhost resistance: Distinct wars with similar arsenals. Phytopathology 105:580-587. 
Glazebrook, J. 2005. Contrasting mechanisms of defense against biotrophic and necrotrophic pathogens. Annu. Rev. Phytopathol. 43:205-227.

Gy, I., Gasciolli, V., Lauressergues, D., Morel, J. B., Gombert, J., Proux, F., Proux, C., Vaucheret, H., and Mallory, A. C. 2007. Arabidopsis FIERY1, XRN2, and XRN3 are endogenous RNA silencing suppressors. Plant Cell 19:3451-3461.

Higashi, K., Ishiga, Y., Inagaki, Y., Toyoda, K., Shiraishi, T., and Ichinose, Y. 2008. Modulation of defense signal transduction by flagellin-induced WRKY41 transcription factor in Arabidopsis thaliana. Mol. Genet. Genomics 279:303-312.

Hirsch, J., Misson, J., Crisp, P. A., David, P., Bayle, V., Estavillo, G. M., Javot, H., Chiarenza, S., Mallory, A. C., Maizel, A., Declerck, M., Pogson, B. J., Vaucheret, H., Crespi, M., Desnos, T., Thibaud, M. C., Nussaume, L., and Marin, E. 2011. A novel fryl allele reveals the existence of a mutant phenotype unrelated to $5^{\prime} \rightarrow 3^{\prime}$ exoribonuclease (XRN) activities in Arabidopsis thaliana roots. PLoS One 6:e16724.

Hiruma, K., Fukunaga, S., Bednarek, P., Pislewska-Bednarek, M., Watanabe, S., Narusaka, Y., Shirasu, K., and Takano, Y. 2013. Glutathione and tryptophan metabolism are required for Arabidopsis immunity during the hypersensitive response to hemibiotrophs. Proc. Natl. Acad. Sci. U.S.A. 110:9589-9594.

Hiruma, K., Onozawa-Komori, M., Takahashi, F., Asakura, M., Bednarek, P., Okuno, T., Schulze-Lefert, P., and Takano, Y. 2010. Entry modedependent function of an indole glucosinolate pathway in Arabidopsis for nonhost resistance against anthracnose pathogens. Plant Cell 22: 2429-2443.

Ishida, M., Hara, M., Fukino, N., Kakizaki, T., and Morimitsu, Y. 2014. Glucosinolate metabolism, functionality and breeding for the improvement of Brassicaceae vegetables. Breed. Sci. 64:48-59.

Ishiga, Y., Ishiga, T., Uppalapati, S. R., and Mysore, K. S. 2011. Arabidopsis seedling flood-inoculation technique: A rapid and reliable assay for studying plant-bacterial interactions. Plant Methods 7:32.

Ishiga, Y., Ishiga, T., Uppalapati, S. R., and Mysore, K. S. 2013. Jasmonate ZIM-domain (JAZ) protein regulates host and nonhost pathogeninduced cell death in tomato and Nicotiana benthamiana. PLoS One 8: e75728.

Ishiga, Y., Ishiga, T., Wangdi, T., Mysore, K. S., and Uppalapati, S. R. 2012. NTRC and chloroplast-generated reactive oxygen species regulate Pseudomonas syringae pv. tomato disease development in tomato and Arabidopsis. Mol. Plant-Microbe Interact 25:294-306.

Ishiga, Y., Uppalapati, S. R., Ishiga, T., Elavarthi, S., Martin, B., and Bender, C. L. 2009. The phytotoxin coronatine induces light-dependent reactive oxygen species in tomato seedlings. New Phytol. 181:147-160.

Katsir, L., Schilmiller, A. L., Staswick, P. E., He, S. Y., and Howe, G. A. 2008. COI1 is a critical component of a receptor for jasmonate and the bacterial virulence factor coronatine. Proc. Natl. Acad. Sci. U.S.A. 105: 7100-7105.

Kim, B. H., and von Arnim, A. G. 2009. FIERY1 regulates light-mediated repression of cell elongation and flowering time via its $3^{\prime}\left(2^{\prime}\right), 5^{\prime}$ bisphosphate nucleotidase activity. Plant J. 58:208-219.

Klaassen, C. D., and Boles, J. W. 1997. Sulfation and sulfotransferases 5: The importance of $3^{\prime}$-phosphoadenosine $5^{\prime}$-phosphosulfate (PAPS) in the regulation of sulfation. FASEB J. 11:404-418.

Kombrink, E. 2012. Chemical and genetic exploration of jasmonate biosynthesis and signaling paths. Planta 236:1351-1366.

Kurihara, Y., Schmitz, R. J., Nery, J. R., Schultz, M. D., Okubo-Kurihara, E., Morosawa, T., Tanaka, M., Toyoda, T., Seki, M., and Ecker, J. R. 2012. Surveillance of $3^{\prime}$ noncoding transcripts requires FIERY1 and XRN3 in Arabidopsis. G3 (Bethesda) 2:487-498.

Lee, B. R., Huseby, S., Koprivova, A., Chételat, A., Wirtz, M., Mugford, S. T., Navid, E., Brearley, C., Saha, S., Mithen, R., Hell, R., Farmer, E. E., and Kopriva, S. 2012. Effects of fou8/fryl mutation on sulfur metabolism: Is decreased internal sulfate the trigger of sulfate starvation response? PLoS One 7:e39425.

Lee, K. P., Kim, C., Landgraf, F., and Apel, K. 2007. EXECUTER1- and EXECUTER2-dependent transfer of stress-related signals from the plastid to the nucleus of Arabidopsis thaliana. Proc. Natl. Acad. Sci. U.S.A. 104:10270-10275.

Lemos, M., Xiao, Y., Bjornson, M., Wang, J. Z., Hicks, D., Souza, Ad., Wang, C. Q., Yang, P., Ma, S., Dinesh-Kumar, S., and Dehesh, K. 2016. The plastidial retrograde signal methyl erythritol cyclopyrophosphate is a regulator of salicylic acid and jasmonic acid crosstalk. J. Exp. Bot. 67: 1557-1566.

Lipka, V., Dittgen, J., Bednarek, P., Bhat, R., Wiermer, M., Stein, M., Landtag, J., Brandt, W., Rosahl, S., Scheel, D., Llorente, F., Molina, A., Parker, J., Somerville, S., and Schulze-Lefert, P. 2005. Pre- and postinvasion defenses both contribute to nonhost resistance in Arabidopsis. Science 310:1180-1183.
Mansfield, J., Genin, S., Magori, S., Citovsky, V., Sriariyanum, M., Ronald, P., Dow, M., Verdier, V., Beer, S. V., Machado, M. A., Toth, I., Salmond, G., and Foster, G. D. 2012. Top 10 plant pathogenic bacteria in molecular plant pathology. Mol. Plant Pathol. 13:614-629.

Nomura, H., Komori, T., Uemura, S., Kanda, Y., Shimotani, K., Nakai, K., Furuichi, T., Takebayashi, K., Sugimoto, T., Sano, S., Suwastika, I. N., Fukusaki, E., Yoshioka, H., Nakahira, Y., and Shiina, T. 2012 Chloroplast-mediated activation of plant immune signalling in Arabidopsis. Nat. Commun. 3:926.

Pieterse, C. M., Van der Does, D., Zamioudis, C., Leon-Reyes, A., and Van Wees, S. C. 2012. Hormonal modulation of plant immunity. Annu. Rev. Cell Dev. Biol. 28:489-521.

Poonam, B., Bhardwaj, R., Kaur, R., Bali, S., Kaur, P., Sirhindi, G., Thukral, A. K., Ohri, P., and Vig, A. P. 2015. Role of various hormones in photosynthetic responses of green plants under environmental stresses. Curr. Protein Pept. Sci. 16:435-449.

Quintero, F. J., Garciadeblás, B., and Rodríguez-Navarro, A. 1996. The SAL1 gene of Arabidopsis, encoding an enzyme with $3^{\prime}\left(2^{\prime}\right), 5^{\prime}$ bisphosphate nucleotidase and inositol polyphosphate 1-phosphatase activities, increases salt tolerance in yeast. Plant Cell 8:529-537.

Robert-Seilaniantz, A., Grant, M., and Jones, J. D. 2011. Hormone crosstalk in plant disease and defense: More than just jasmonate-salicylate antagonism. Annu. Rev. Phytopathol. 49:317-343.

Robles, P., Fleury, D., Candela, H., Cnops, G., Alonso-Peral, M. M., Anami, S., Falcone, A., Caldana, C., Willmitzer, L., Ponce, M. R., Van Lijsebettens, M., and Micol, J. L. 2010. The RON1/FRY1/SAL1 gene is required for leaf morphogenesis and venation patterning in Arabidopsis. Plant Physiol. 152:1357-1372.

Rodríguez, V. M., Chételat, A., Majcherczyk, P., and Farmer, E. E. 2010. Chloroplastic phosphoadenosine phosphosulfate metabolism regulates basal levels of the prohormone jasmonic acid in Arabidopsis leaves. Plant Physiol. 152:1335-1345.

Rossel, J. B., Walter, P. B., Hendrickson, L., Chow, W. S., Poole, A., Mullineaux, P. M., and Pogson, B. J. 2006. A mutation affecting ASCORBATE PEROXIDASE 2 gene expression reveals a link between responses to high light and drought tolerance. Plant Cell Environ. 29: 269-281.

Senthil-Kumar, M., and Mysore, K. S. 2013. Nonhost resistance against bacterial pathogens: Retrospectives and prospects. Annu. Rev. Phytopathol. 51:407-427.

Stein, M., Dittgen, J., Sánchez-Rodríguez, C., Hou, B. H., Molina, A., Schulze-Lefert, P., Lipka, V., and Somerville, S. 2006. Arabidopsis PEN3/PDR8, an ATP binding cassette transporter, contributes to nonhost resistance to inappropriate pathogens that enter by direct penetration. Plant Cell 18:731-746.

Stotz, H. U., Sawada, Y., Shimada, Y., Hirai, M. Y., Sasaki, E., Krischke, M., Brown, P. D., Saito, K., and Kamiya, Y. 2011. Role of camalexin, indole glucosinolates, and side chain modification of glucosinolatederived isothiocyanates in defense of Arabidopsis against Sclerotinia sclerotiorum. Plant J. 67:81-93.

Sun, Y., and Zerges, W. 2015. Translational regulation in chloroplasts for development and homeostasis. Biochim. Biophys. Acta 1847:809-820.

Tikkanen, M., Gollan, P. J., Suorsa, M., Kangasjärvi, S., and Aro, E. M. 2012. STN7 operates in retrograde signaling through controlling redox balance in the electron transfer chain. Front. Plant Sci. 3:277.

Tohge, T., and Fernie, A. R. 2010. Combining genetic diversity, informatics and metabolomics to facilitate annotation of plant gene function. Nat. Protoc. 5:1210-1227

Tsuda, K., and Katagiri, F. 2010. Comparing signaling mechanisms engaged in pattern-triggered and effector-triggered immunity. Curr Opin. Plant Biol. 13:459-465.

Tsukahara, K., Sawada, H., Kohno, Y., Matsuura, T., Mori, I. C., Terao, T., Ioki, M., and Tamaoki, M. 2015. Ozone-induced rice grain yield loss is triggered via a change in panicle morphology that is controlled by ABERRANT PANICLE ORGANIZATION 1 gene. PLoS One 10: e0123308.

Uppalapati, S. R., Ishiga, Y., Wangdi, T., Kunkel, B. N., Anand, A., Mysore, K. S., and Bender, C. L. 2007. The phytotoxin coronatine contributes to pathogen fitness and is required for suppression of salicylic acid accumulation in tomato inoculated with Pseudomonas syringae pv. tomato DC3000. Mol. Plant-Microbe Interact 20:955-965.

Watanabe, M., Balazadeh, S., Tohge, T., Erban, A., Giavalisco, P., Kopka, J., Mueller-Roeber, B., Fernie, A. R., and Hoefgen, R. 2013. Comprehensive dissection of spatiotemporal metabolic shifts in primary, secondary, and lipid metabolism during developmental senescence in Arabidopsis. Plant Physiol. 162:1290-1310.

Wilson, P. B., Estavillo, G. M., Field, K. J., Pornsiriwong, W., Carroll, A. J., Howell, K. A., Woo, N. S., Lake, J. A., Smith, S. M., Harvey Millar, A., 
von Caemmerer, S., and Pogson, B. J. 2009. The nucleotidase/phosphatase SAL1 is a negative regulator of drought tolerance in Arabidopsis. Plant J. 58:299-317.

Xiao, Y., Savchenko, T., Baidoo, E. E., Chehab, W. E., Hayden, D. M., Tolstikov, V., Corwin, J. A., Kliebenstein, D. J., Keasling, J. D., and Dehesh, K. 2012. Retrograde signaling by the plastidial metabolite $\mathrm{MEcPP}$ regulates expression of nuclear stress-response genes. Cell 149: 1525-1535.

Xiong, L., Lee, Bh, Ishitani, M., Lee, H., Zhang, C., and Zhu, J. K. 2001. FIERY1 encoding an inositol polyphosphate 1-phosphatase is a negative regulator of abscisic acid and stress signaling in Arabidopsis. Genes Dev 15:1971-1984.

Zhang, J., and Zhou, J. M. 2010. Plant immunity triggered by microbial molecular signatures. Mol. Plant 3:783-793.

Zhao, Y., Thilmony, R., Bender, C. L., Schaller, A., He, S. Y., and Howe, G. A. 2003. Virulence systems of Pseudomonas syringae pv. tomato promote bacterial speck disease in tomato by targeting the jasmonate signaling pathway. Plant J. 36:485-499.

Zipfel, C. 2008. Pattern-recognition receptors in plant innate immunity. Curr. Opin. Immunol. 20:10-16. 